\title{
Methylmercury production below the mixed layer in the North Pacific Ocean
}

\author{
Joel D. Blum ${ }^{1 \star}$, Brian N. Popp², Jeffrey C. Drazen ${ }^{3}$, C. Anela Choy ${ }^{3}$ and Marcus W. Johnson ${ }^{1}$
}

\begin{abstract}
Mercury enters marine food webs in the form of microbially generated monomethylmercury. Microbial methylation of inorganic mercury, generating monomethylmercury, is widespread in low-oxygen coastal sediments. The degree to which microbes also methylate mercury in the open ocean has remained uncertain, however. Here, we present measurements of the stable isotopic composition of mercury in nine species of marine fish that feed at different depths in the central North Pacific Subtropical Gyre. We document a systematic decline in $\delta^{202} \mathrm{Hg}, \Delta^{199} \mathrm{Hg}$ and $\Delta^{201} \mathrm{Hg}$ values with the depth at which fish feed. We show that these mercury isotope trends can be explained only if monomethylmercury is produced below the surface mixed layer, including in the underlying oxygen minimum zone, that is, between $\mathbf{5 0}$ and more than $\mathbf{4 0 0} \mathrm{m}$ depth. Specifically, we estimate that about $\mathbf{2 0 - 4 0 \%}$ of the monomethylmercury detected below the surface mixed layer originates from the surface and enters deeper waters either attached to sinking particles, or in zooplankton and micronekton that migrate to depth. We suggest that the remaining monomethylmercury found at depth is produced below the surface mixed layer by methylating microbes that live on sinking particles. We suggest that microbial production of monomethylmercury below the surface mixed later contributes significantly to anthropogenic mercury uptake into marine food webs.
\end{abstract}

M ercury $(\mathrm{Hg})$ is a globally distributed atmospheric pollutant that can form monomethyl-Hg (MMHg), which is neurotoxic and bioaccumulative in aquatic food webs. The main pathway for human exposure to $\mathrm{MMHg}$ is through consumption of piscivorous marine fish ${ }^{1}$. In the ocean $\mathrm{Hg}$ primarily exists as inorganic $\mathrm{Hg}(\mathrm{II})$ or $\mathrm{Hg}(0)_{\mathrm{aq}}$, but microbial reactions can methylate $\mathrm{Hg}$ (II) to $\mathrm{MMHg}$ and dimethyl-Hg (DMHg), and microbial and photochemical processes can degrade MMHg and DMHg back to $\mathrm{Hg}(\mathrm{II})$ or $\mathrm{Hg}(0)_{\mathrm{aq}}$ (ref. 2). In the North Pacific Ocean these processes result in nutrient-like vertical concentration profiles for methylated mercury, with very low concentrations in open ocean surface waters and higher concentrations in subthermocline low- $\mathrm{O}_{2}$ deeper intermediate waters ${ }^{3,4}$. Similar profiles have also been documented in the Equatorial Pacific, Mediterranean Sea and Southern Ocean ${ }^{5-7}$. In agreement with these vertical profiles, total $\mathrm{Hg}$ ( $\mathrm{THg}$ ) levels in commercially important predatory pelagic fish and their prey increase with median depth of occurrence ${ }^{8,9}$, which is indicative of both foraging depth and habitat utilization. However, the biogeochemical factors controlling the distribution and speciation of $\mathrm{Hg}$ in the ocean and the bioaccumulation of $\mathrm{MMHg}$ in marine food webs are still not well understood ${ }^{10}$.

Microbial activity and both dark and photochemical inorganic reactions ultimately control the chemical speciation and subsequent bioavailability of $\mathrm{Hg}$ (ref. 2), thus an understanding of the competing processes that produce and degrade MMHg at different depths in the ocean is critical to tracing its bioaccumulation in fish and biomagnification in marine food webs. MMHg typically comprises only a small fraction of THg in North Pacific sea water ( $<15 \%$; ref. 4 ) but nearly all of the $\mathrm{Hg}(>95 \%)$ in large marine fish $^{2,11}$ and most of the $\mathrm{Hg}(>80 \%)$ in small fish with trophic position (TP) as low as 2.5 (ref. 12). DMHg concentrations are generally small relative to $\mathrm{MMHg}$ (refs 3,4,13), although at some marine locations DMHg can be a significant fraction of $\mathrm{MMHg}$ (refs 13,14). As DMHg is not bioaccumulated and because its $\mathrm{Hg}$ isotopic composition has not been measured, it is not treated in detail here. MMHg production in the oxygen minimum zone (OMZ) of the oceanic water column has been hypothesized ${ }^{7,13}$ and recent field studies have offered new evidence supporting in situ methylation not only in OMZs (refs 3,6) but also in oxic surface waters ${ }^{4,5,15-17}$. Vertical differences in ocean biogeochemistry and the relative contributions of different $\mathrm{Hg}$ sources to the overall $\mathrm{MMHg}$ burdens in fish have wide-ranging implications for understanding how $\mathrm{MMHg}$ levels in marine biota will respond to future changes in anthropogenic $\mathrm{Hg}$ emissions ${ }^{3,18}$.

Mercury isotope ratios can provide insight into the biogeochemical cycling of $\mathrm{Hg}$ (refs 19,20). Mercury displays mass-dependent fractionation (MDF; $\delta^{202} \mathrm{Hg}$ ) during all biotic and abiotic chemical reactions that have been investigated and large magnitude mass-independent fractionation (MIF; $\Delta^{199} \mathrm{Hg}, \Delta^{201} \mathrm{Hg}$ ) during photochemical radical pair reactions (see Methods for definition of $\delta^{202} \mathrm{Hg}, \Delta^{199} \mathrm{Hg}$ and $\Delta^{201} \mathrm{Hg}$ ). The combination of $\mathrm{Hg} \mathrm{MDF}$ and MIF provides a probe into the reaction pathways and biogeochemical history of $\mathrm{Hg}$ and can also provide a fingerprint of sources of $\mathrm{Hg}$ to ecosystems ${ }^{19-22}$. Coupling estimates of TP with $\mathrm{Hg}$ concentrations can allow for an understanding of $\mathrm{MMHg}$ biomagnification in marine food webs ${ }^{5,21}$.

Here we measured the $\mathrm{Hg}$ isotopic compositions and established TPs of pelagic fish from the North Pacific Subtropical Gyre (NPSG) near Hawaii, for which $\mathrm{Hg}$ concentration and median depth of occurrence were known (Supplementary Tables S1 and S2) ${ }^{8}$. We used amino acid compound-specific $\mathrm{N}$ isotope analyses (AACSIA) to establish organism TP because this technique provides information on time-integrated TP independent of the $\delta^{15} \mathrm{~N}$ values at the base of the food web ${ }^{23}$. Our aim was to use MDF $\left(\delta^{202} \mathrm{Hg}\right)$ and $\operatorname{MIF}\left(\Delta^{199} \mathrm{Hg}, \Delta^{201} \mathrm{Hg}\right)$ of $\mathrm{Hg}$ in a suite of fish feeding at

\footnotetext{
${ }^{1}$ Department of Earth and Environmental Sciences, University of Michigan, 1100 N University Avenue, Ann Arbor, Michigan 48109, USA, ${ }^{2}$ Department of Geology and Geophysics, University of Hawaii, 1680 East-West Road, Honolulu, Hawaii 96822, USA, ${ }^{3}$ Department of Oceanography, University of Hawaii, 1000 Pope Road, Honolulu, Hawaii 96822, USA. *e-mail: jdblum@umich.edu
} 
different depths and across different TPs to test hypotheses for the depth of microbial Hg methylation, and both microbial and photochemical $\mathrm{Hg}$ demethylation, before introduction into the pelagic marine food web.

\section{Species sampled and their depth of occurrence}

We analysed samples of muscle tissue from either three or four individuals from each of nine species of fish (six high-TP predatory species, three low-TP prey species; Supplementary Table S1 for species names and data on core depth ranges and median depths of occurrence) collected in the central NPSG near Hawaii and previously analysed for $\mathrm{THg}$ concentrations ${ }^{8}$. Electronic tagging and trawling studies provide very useful information on vertical habitat utilization. Median depth of occurrence based on core day and night depth ranges taken from the literature for the species we sampled range from 10 to $590 \mathrm{~m}$. Accurately estimating depth of forage is difficult due to complexities in daily vertical migrations, periodic deep dives by some species and vertical movements of prey, among other factors. Nonetheless it is our view that the best approach to represent the range of habitats (and probable foraging depth ranges) used by these species is the median depth of occurrence.

\section{Mercury isotope variation in Pacific ocean fish}

Irrespective of the complexities in estimates of mean depths of occurrence mentioned above, we observe a systematic decrease in $\delta^{202} \mathrm{Hg}, \Delta^{199} \mathrm{Hg}$ and $\Delta^{201} \mathrm{Hg}$ values with median depth (Fig. 1a,b and Supplementary Tables S1 and S2). Mean THg concentrations in muscle tissue range from $16.9 \mathrm{ng} \mathrm{g}^{-1}$ (wet weight) in flying fish to $1,586 \mathrm{ng} \mathrm{g}^{-1}$ (wet weight) in swordfish. The shallowest occurring fish (flying fish) have average $\mathrm{Hg}$ isotope values of $\delta^{202} \mathrm{Hg}=1.5 \%$, $\Delta{ }^{199} \mathrm{Hg}=5.3 \%$ and $\Delta^{201} \mathrm{Hg}=4.3 \%$; much higher than values for the deepest occurring fish (lanternfish-distofax), which average $\delta^{202} \mathrm{Hg}=0.2 \%, \Delta^{199} \mathrm{Hg}=1.5 \%$ and $\Delta^{201} \mathrm{Hg}=1.2 \%$.

Laboratory experiments reveal that microbial methylation produces $\mathrm{MMHg}$ with $\delta^{202} \mathrm{Hg}$ values lower than that of the reactant $\mathrm{Hg}$ (II) (ref. 24) and microbial demethylation leaves residual $\mathrm{MMHg}$ with higher $\delta^{202} \mathrm{Hg}$ values than reactant $\mathrm{MMHg}$ (ref. 25). Furthermore, microbial reactions do not produce changes in values of $\Delta^{199} \mathrm{Hg}$ or $\Delta^{201} \mathrm{Hg}$ (ref. 25). In contrast, photochemical degradation of $\mathrm{MMHg}$ in fresh water complexed with natural dissolved organic carbon (DOC) causes increases in $\delta^{202} \mathrm{Hg}, \Delta^{199} \mathrm{Hg}$ and $\Delta^{201} \mathrm{Hg}$ values in the residual $\mathrm{MMHg}$ with an experimentally derived $\Delta^{199} \mathrm{Hg} / \delta^{202} \mathrm{Hg}$ ratio of $2.43 \pm 0.10$ and $\Delta^{199} \mathrm{Hg} / \Delta^{201} \mathrm{Hg}$ ratio of $1.34 \pm 0.04$ (ref. 20). Photochemical reduction of $\mathrm{Hg}$ (II) in fresh water complexed with natural DOC yields residual $\mathrm{Hg}$ (II) with an experimentally derived $\Delta^{199} \mathrm{Hg} / \delta^{202} \mathrm{Hg}$ ratio of $1.15 \pm 0.07$ and $\Delta^{199} \mathrm{Hg} / \Delta^{201} \mathrm{Hg}$ ratio of $1.00 \pm 0.01$ (ref. 20). Published experiments have not been carried out in sea water or at marine $\mathrm{MMHg} / \mathrm{DOC}$ ratios, but those in fresh water are adequate to guide the general interpretation of isotopic trends observed in natural systems ${ }^{20-22,26-30}$.

Although photochemical degradation of MMHg is an important process in the upper ocean ${ }^{16,21}$, degradation by microbes may also be important ${ }^{25}$. Our measured trends of $\mathrm{Hg}$ isotope values in fish can be used to test whether microbial or photochemical degradation of $\mathrm{MMHg}$ is the dominant process affecting $\mathrm{MMHg}$ before it enters the food web. The $\Delta^{199} \mathrm{Hg} / \delta^{202} \mathrm{Hg}$ ratio in the fish we analysed is $2.64 \pm 0.24$ (Fig. $2 \mathrm{a}$ ), close to the experimentally derived ratio of $2.43 \pm 0.10$ for photochemical degradation ${ }^{20}$ and the data fall on a linear trend. If the dominant demethylation process was microbial we would expect a slope not statistically different from 0 and if both processes were important we would expect a slope intermediate between 0 and 2.43, with considerable scatter if the relative importance of these processes changed with water depth. We estimate based on experimentally derived fractionation
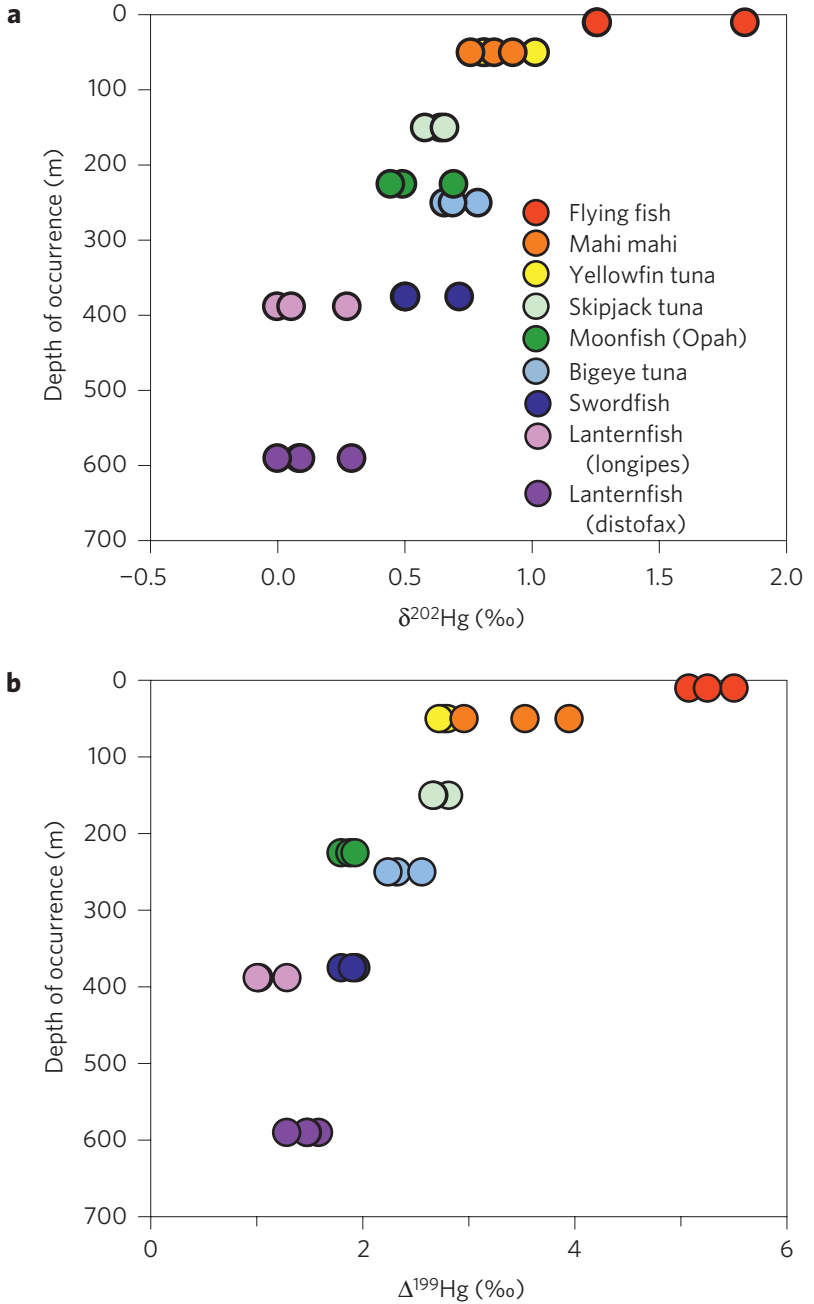

Figure 1 | Mercury isotope diagrams illustrating MDF and MIF variation in fish with depth. a,b, $\delta^{202} \mathrm{Hg}$ (a) and $\Delta^{199} \mathrm{Hg}(\mathbf{b})$ values (in permil) for fish from the NPSG near Hawaii plotted as a function of median depth of occurrence (in metres) for six species of predatory pelagic fish, as well as surface-dwelling flying fish and two species of lanternfish that undergo diel vertical migration.

factors that the deviation of isotopic compositions from the linear trend on Fig. 2a can accommodate a maximum of $\sim 15 \%$ microbial demethylation $^{25,31}$, with most owing to photochemical degradation. As the linear array of data on the plot of $\delta^{202} \mathrm{Hg}$ versus $\Delta^{199} \mathrm{Hg}$ is caused primarily by photochemical degradation, the regressed line should pass through the isotopic composition of $\mathrm{MMHg}$ that occurred before marine photochemical degradation. On Fig. 2a we also plot the range of measured $\mathrm{Hg}$ isotopic compositions in precipitation on the west coasts of California ${ }^{32}$ and Florida ${ }^{33}$ (which reveal only a small amount of atmospheric photochemical MIF). If the $\delta^{202} \mathrm{Hg}$ values of $\mathrm{Hg}(\mathrm{II})$ in precipitation were decreased by $\sim 0.5 \%$ during microbial methylation (as observed in laboratory experiments ${ }^{24}$ ) they would be compatible with the predicted values for marine $\mathrm{MMHg}$ before any photochemical degradation (Fig. 2a).

The $\Delta^{199} \mathrm{Hg} / \Delta^{201} \mathrm{Hg}$ ratio can be diagnostic of reactions that cause $\mathrm{Hg}$ MIF. $\Delta^{201} \mathrm{Hg}$ is highly correlated with $\Delta^{199} \mathrm{Hg}$ for all marine fish that have been analysed including those from the Gulf of Mexico ${ }^{21}$, San Francisco Bay estuary ${ }^{30}$ and the NPSG (this study), with a slope of $1.20 \pm 0.01$ (Fig. 2b). These field results suggest that photochemical degradation mechanisms are similar 

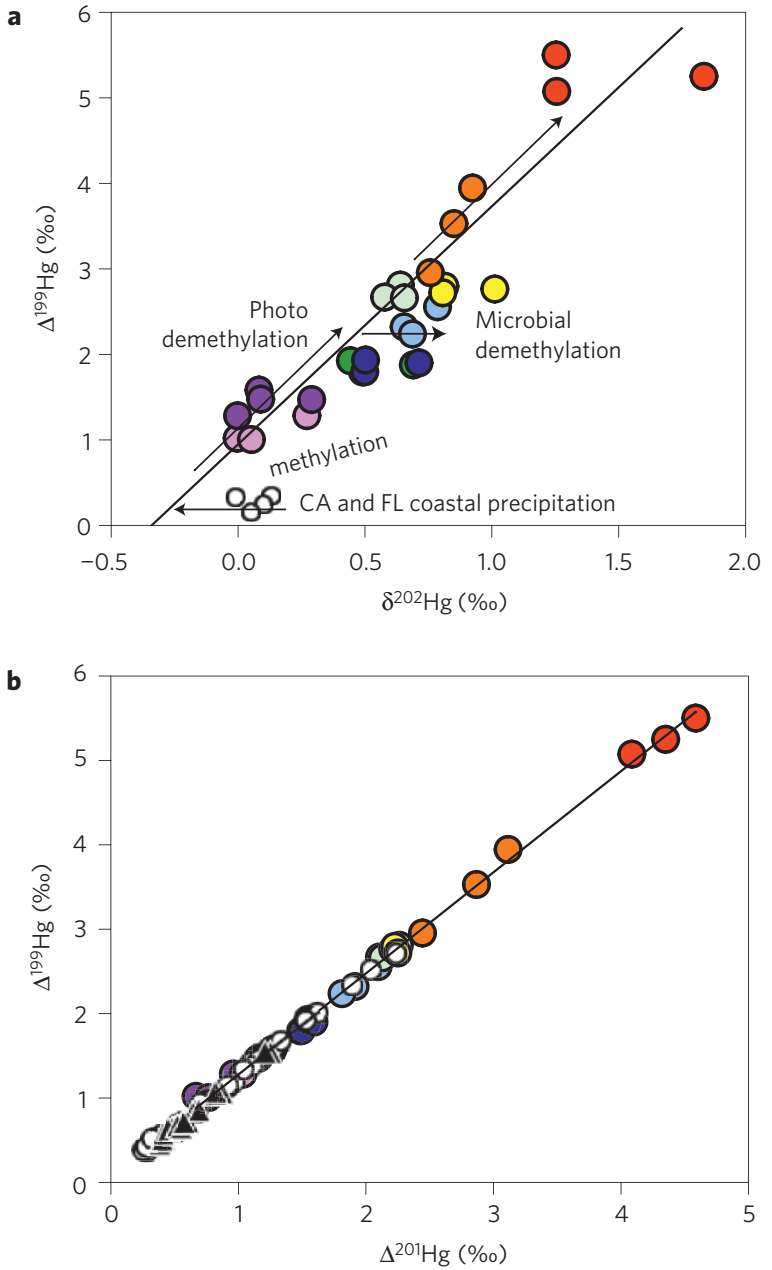

Figure 2 | Mercury isotope diagrams illustrating correlations between MIF and MDF and between MIF of $\Delta^{199} \mathrm{Hg}$ and MIF of $\Delta^{201} \mathbf{H g} . \mathbf{a}, \mathbf{b}, \delta^{202} \mathrm{Hg}$ versus $\Delta^{199} \mathrm{Hg}$ values (a) and $\Delta^{201} \mathrm{Hg}$ versus $\Delta^{199} \mathrm{Hg}$ values $(\mathbf{b})$ for the marine fish shown in Fig. 1 using the same symbols as in Fig. 1. Also shown in a are values for $\delta^{202} \mathrm{Hg}$ and $\Delta^{199} \mathrm{Hg}$ in coastal precipitation (white circles) from California ${ }^{32}$ and Florida ${ }^{33}$, and the estimated shift in values due to microbial methylation ${ }^{24}$ before photochemical degradation, and due to $\sim 15 \%$ microbial demethylation ${ }^{25}$ following photochemical degradation (black arrows). Also plotted in $\mathbf{b}$ are marine fish from the Gulf of Mexico ${ }^{21}$ (white circles) and the San Francisco estuary ${ }^{30}$ (triangles).

at these diverse marine sites, which include coastal and open ocean environments. In comparison, the $\Delta^{199} \mathrm{Hg} / \Delta^{201} \mathrm{Hg}$ ratio obtained in $\mathrm{MMHg}$ photochemical degradation experiments (with $1 \mathrm{mgl}^{-1}$ freshwater DOC) was $1.36 \pm 0.04$ (ref. 20). Analyses of fish from lakes yield a wider range of $\Delta^{199} \mathrm{Hg} / \Delta^{201} \mathrm{Hg}(0.99-1.33$; refs 20,26-29), but most are $\sim 1$.3. Investigations have shown that variation in the $\Delta^{199} \mathrm{Hg} / \Delta^{201} \mathrm{Hg}$ ratio during photochemical reduction of $\mathrm{Hg}$ (II) can depend on the organic ligand to which $\mathrm{Hg}(\mathrm{II})$ is bonded ${ }^{34}$. It seems likely that a similar phenomenon occurs with $\mathrm{MMHg}$ and that this explains the slightly higher experimentally derived $\Delta^{199} \mathrm{Hg} / \Delta^{201} \mathrm{Hg}$ ratio compared with what is observed in marine fish.

The high $\Delta^{199} \mathrm{Hg}$ (and $\Delta^{201} \mathrm{Hg}$ and $\delta^{202} \mathrm{Hg}$ ) values in surfaceforaging fish and the decreases in all three isotope values with increasing fish depth of occurrence clearly supports the hypothesis that $\mathrm{MMHg}$ at shallower depths undergoes a greater extent of photochemical degradation before introduction into the marine food web compared with MMHg at greater depths (Figs 1-2).
Mapping observed $\Delta^{199} \mathrm{Hg}$ values to experimental data ${ }^{20}$ and to a proposed extrapolation of these data to the $\mathrm{MMHg} / \mathrm{DOC}$ ratio of North Pacific surface water ${ }^{22}$ suggests that these fish preserve the isotopic composition of residual $\mathrm{MMHg}$ that has undergone between 46 and $80 \%$ photochemical degradation at a mean depth of $10 \mathrm{~m}$ and between 9 and $21 \%$ photochemical degradation at a depth of $590 \mathrm{~m}$ (Methods). Estimates of percentage photochemical degradation could be even higher for lower TP fish, which may have up to $20 \%$ inorganic $\mathrm{Hg}$ (ref. 12), but this does not change our interpretation of the data appreciably.

We investigated the effects of biomagnification on $\mathrm{Hg}$ concentration and isotopic compositions using our estimated TPs for the fish (Supplementary Table S3). There is a significant positive correlation between $\mathrm{TP}$ and $\mathrm{THg}\left(R^{2}=0.78\right)$, but there is not a significant correlation between TP and $\Delta^{199} \mathrm{Hg}$ values $\left(R^{2}=0.079\right)$ or $\delta^{202} \mathrm{Hg}$ values $\left(R^{2}=0.003\right.$; data given in Supplementary Tables S2 and S3). This is consistent with the conclusion of a previous study ${ }^{35}$ that trophic transfer does not result in appreciable isotopic fractionation of $\mathrm{Hg}$ and demonstrates that, although feeding ecology can be an important factor controlling marine fish $\mathrm{Hg}$ levels, trophic transfer does not significantly affect $\mathrm{Hg}$ isotope values.

\section{Implications for $\mathrm{Hg}$ biogeochemical cycling in the ocean}

Our measurement of the depth dependence of the Hg isotopic composition of fish from the NPSG has implications for models of $\mathrm{MMHg}$ production and degradation in the open ocean. The trends in $\delta^{202} \mathrm{Hg}$ and $\Delta^{199} \mathrm{Hg}$ values (Fig. 1) cannot be explained by production of MMHg exclusively in the photic zone, deposition of $\mathrm{MMHg}$ from the atmosphere, or lateral advection of $\mathrm{MMHg}$ from coastal regions. In these cases we would not expect to see sharp decreases with depth in $\Delta^{199} \mathrm{Hg}$ and $\Delta^{201} \mathrm{Hg}$ values in fish, because there is no known mechanism in aquatic systems to erase the MIF signal imparted by photochemical degradation in the photic zone, except through dilution by newly formed $\mathrm{MMHg}$ at depth. Instead, the $\mathrm{Hg}$ isotope data require that methylation occurs below the surface mixed layer (SML), in agreement with a previous study of $\mathrm{MMHg} / \mathrm{P}$ ratios in open Mediterranean waters ${ }^{6}$.

Photochemical demethylation leaves a residual pool of unreacted MMHg with increased $\delta^{202} \mathrm{Hg}, \Delta^{199} \mathrm{Hg}$ and $\Delta^{201} \mathrm{Hg}$ values, which is available for bioaccumulation. $\Delta^{199} \mathrm{Hg}$ and $\Delta^{201} \mathrm{Hg}$ values can be lowered only by addition of MMHg that has undergone very little or no photochemical degradation before bioaccumulation. Therefore, if all MMHg was formed in the SML it would be expected to show high positive values of $\Delta^{199} \mathrm{Hg}$ and $\Delta^{201} \mathrm{Hg}$ owing to exposure to sunlight in the photic zone, and this signature would be retained in $\mathrm{Hg}$ exported to greater depths. Decline of $\Delta^{199} \mathrm{Hg}$ values with depth must, therefore, be a consequence of $\mathrm{MMHg}$ production below the SML, probably on sinking particles of organic matter ${ }^{3,7,17}$, which does not undergo photochemical degradation and mixes with residual photodegraded $\mathrm{MMHg}$ exported to depth from the SML either attached to sinking particles or by zooplankton and micronekton that undergo diel vertical migration. Fish from $590 \mathrm{~m}$ depth preserve a highly attenuated, but still clearly identifiable, MIF signature attributable to photochemical demethylation. A simplified depiction of our model for $\mathrm{Hg}$ deposition, methylation, photodemethylation and incorporation into the marine food web is shown in Fig. 3.

$\Delta^{199} \mathrm{Hg}$ values of MMHg in the deep ocean $(\sim 590 \mathrm{~m})$ food web can be explained using a simple mixing calculation as a combination of $20-40 \% \mathrm{MMHg}$ from the SML foodweb and $60-80 \% \mathrm{MMHg}$ formed below the SML in the pycnocline (Fig. 3). Published depth profiles of $\mathrm{MMHg}$ from the central Pacific ${ }^{3,4}$ show increases with depth from $\sim 20$ to $50 \mathrm{fM}$ near the surface to $\sim 40$ to $400 \mathrm{fM}$ at $600 \mathrm{~m}$ depth. Our results indicate that between 46 and $80 \%$ of 


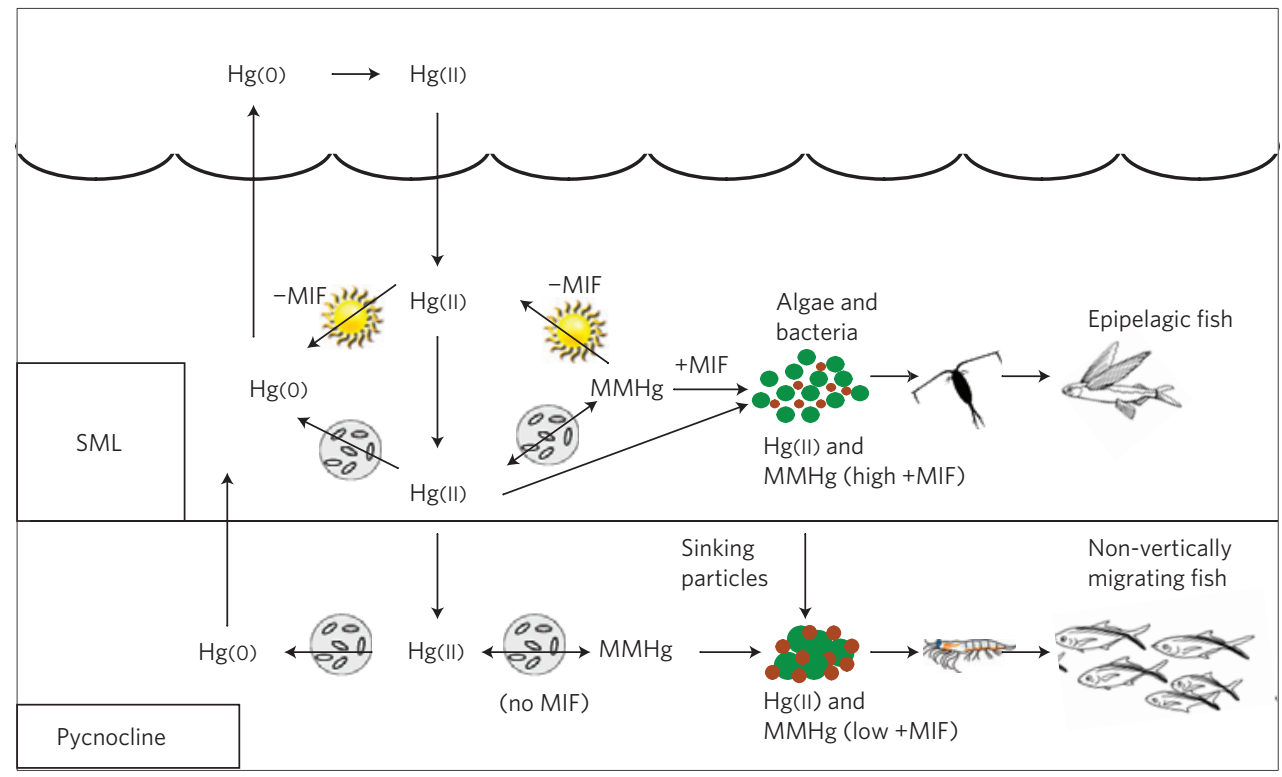

Figure 3 | Schematic representation of a simplified model for $\mathrm{Hg}$ cycling between atmosphere, SML, pycnocline and marine food web. $\mathrm{Hg}(\mathrm{II})$ is deposited from precipitation to the ocean surface, where some is photochemically reduced to $\mathrm{Hg}(0)$, some is microbially reduced, some is microbially methylated to $\mathrm{MMHg}$ and some is transported to greater depths attached to particles. Photochemical degradation of MMHg in the SML leaves a residual MMHg pool with high positive values of MIF that is propagated through the shallow-water food web to epipelagic fish. Sinking particles carry MMHg with MIF and $\mathrm{Hg}(\mathrm{II})$ without significant MIF to the pycnocline where additional microbial methylation occurs, producing additional MMHg without MIF, which dilutes the MIF in MMHg exported from the SML, resulting in MMHg with lower positive values of MIF. Thus MMHg with lower MIF is incorporated into the mesopelagic food web and therefore to deeper foraging fish.

MMHg produced in the photic zone is photodegraded there and that $60-80 \%$ of $\mathrm{MMHg}$ bioaccumulated at $590 \mathrm{~m}$ is produced below the SML. Thus the observed MMHg vertical concentration gradient could primarily be attributed to increased photochemical degradation near the surface. There is supporting evidence from $\mathrm{MMHg}$ mass balance calculations for production of significant amounts of MMHg in the mixed layer. It has been suggested ${ }^{4,10}$ that the vertical flux of MMHg in the North Pacific is small compared with rates of bioaccumulation and photochemical degradation; in agreement with the $\mathrm{Hg}$ isotopic results, horizontal transport of $\mathrm{MMHg}$ by surface currents is considered to be minor ${ }^{10}$. MMHg concentration profiles between the SML and $\sim 600 \mathrm{~m}$ were used to model the vertical flux of $\mathrm{MMHg}$ to surface water and estimated rates of bioaccumulation and of photochemical degradation of $\mathrm{MMHg}$ in surface waters greatly exceeded this vertical flux ${ }^{4}$. This conclusion is consistent with our $\mathrm{Hg}$ isotopic data that suggest $\mathrm{MMHg}$ production in the mixed layer and down to a depth of $590 \mathrm{~m}$ within the OMZ (>400 m).

It is unknown how the balance of increased fossil fuel use and improving emissions control technologies will affect future anthropogenic $\mathrm{Hg}$ emissions. But it has been suggested that $\mathrm{Hg}$ concentrations in surface and shallow subsurface waters of the Pacific Ocean will change significantly over the next few decades ${ }^{3,10}$. For example, it has been predicted ${ }^{3}$ that the concentration of $\mathrm{THg}$ mercury in North Pacific intermediate waters $(200-1,000 \mathrm{~m}$ depth) will double by the year 2050, relative to 1995, assuming contemporary atmospheric $\mathrm{Hg}$ deposition rates. Increases in $\mathrm{Hg}$ concentrations in the SML of the North Pacific are more difficult to predict because they are sensitive to regionally variable meteorological and chemical factors that control the oxidation of $\mathrm{Hg}(0)$ and the transport and deposition of $\mathrm{Hg}(\mathrm{II})$ (ref. 3). The extent to which atmospheric deposition of anthropogenic Hg may impact marine fisheries will depend in part on the depth(s) at which inorganic $\mathrm{Hg}$ is converted to organic $\mathrm{Hg}$ and at which $\mathrm{MMHg}$ enters the food web and subsequently bioaccumulates. Moreover, in the Pacific (and other oceans), OMZs are expanding ${ }^{36,37}$. Understanding $\mathrm{Hg}$ biogeochemical cycling in these environments is crucial for the prediction of potential consequences for marine ecosystems. We suggest that, because of photochemical degradation in the mixed layer, the greatest input of $\mathrm{MMHg}$ to food webs occurs below the mixed layer and results in the observed increases in $\mathrm{Hg}$ concentration of high-trophic-level fish from the mixed layer down to the OMZ.

\section{Methods}

Hg concentrations. Total Hg levels in homogenized freeze-dried samples were measured by thermal decomposition, gold amalgamation and atomic absorption spectroscopy (Milestone, DMA-80) as described in US Environmental Protection Agency Method 7473. One in every ten samples was analysed in replicate and the lower limit of quantification was $\sim 0.2 \mathrm{ng} \mathrm{g}^{-1}$.

Hg isotope ratios. $\mathrm{Hg}$ isotopic analyses were carried out on freeze-dried homogenized samples using methods previously described in detail ${ }^{19-21,29,30,35}$ Briefly, samples were placed in a combustion furnace that was ramped to a maximum temperature of $750^{\circ} \mathrm{C}, \mathrm{Hg}(0)$ vapour was transported in a stream of air and $\mathrm{O}_{2}$ through a second furnace held at $1,000^{\circ} \mathrm{C}$ and the gas stream was then bubbled into a solution of $1 \% \mathrm{KMnO}_{4}$ where $\mathrm{Hg}(0)$ was oxidized and retained as $\mathrm{Hg}(\mathrm{II})$. Following combustion, $1 \% \mathrm{KMnO}_{4}$ solutions were neutralized with $\mathrm{NH}_{2} \mathrm{OH}$ and $\mathrm{SnCl}_{2}$ and $\mathrm{Hg}(0)$ was sparged with Ar gas into another $1 \% \mathrm{KMnO}_{4}$ solution to obtain a complete separation of $\mathrm{Hg}$ from other combustion products. These $\mathrm{KMnO}_{4}$ solutions were neutralized with $\mathrm{NH}_{2} \mathrm{OH}$ and $\mathrm{Hg}$ concentrations were determined using a Nippon Instruments MA-2000 amalgamation-atomic absorption spectrometer to determine $\mathrm{Hg}$ separation yields. Replicate combustions of samples and standard reference materials were made along with procedural blanks. $\mathrm{Hg}$ isotopic compositions were determined on a $\mathrm{Nu}$ Instruments multicollector inductively coupled plasma mass spectrometer (MC-ICP-MS). $\mathrm{KMnO}_{4}$ sample solutions were diluted to between 1 and $5 \mathrm{ng} \mathrm{g}^{-1}$ and a National Institute of Standards and Technology (NIST) 3133 standard was matched to samples by matrix and $\mathrm{Hg}$ concentration. $\mathrm{KMnO}_{4}$ solutions were partially neutralized with $\mathrm{NH}_{2} \mathrm{OH}$ and then further reduced by $\mathrm{SnCl}_{2}$ online. Reduced $\mathrm{Hg}(0)$ was separated from solution using an online phase separator and introduced to the MC-ICP-MS in a stream of Ar gas. Instrumental mass bias was corrected using an internal Tl standard (NIST 997) added as an aerosol to the gas stream and sample-standard bracketing was carried out with NIST 3133. On-peak zero corrections were applied to all analyses. 
$\mathrm{Hg}$ isotope nomenclature. $\mathrm{Hg}$ isotopic ratios are reported in permil, referenced to the NIST 3133 standard, where:

$$
\delta^{x x x} \mathrm{Hg}=\left\{\left[\left({ }^{x x x} \mathrm{Hg} /{ }^{198} \mathrm{Hg}\right)_{\text {sample }} /\left({ }^{x x x} \mathrm{Hg} /{ }^{198} \mathrm{Hg}\right)_{\text {NIST3133 }}\right]-1\right\} \times 1,000
$$

and $x x x$ equals 199,201 or 202. MDF is reported as $\delta^{202} \mathrm{Hg}$.

MIF represents the difference between the measured $\delta^{x x x} \mathrm{Hg}$ values and the values predicted based on MDF and the $\delta^{202} \mathrm{Hg}$ value. MIF is reported as $\Delta^{199} \mathrm{Hg}$ and $\Delta^{201} \mathrm{Hg}$ in permil. For $\delta<10 \%$ a valid approximation is ${ }^{19}$ :

$$
\begin{aligned}
& \Delta^{199} \mathrm{Hg}=\delta^{199} \mathrm{Hg}-\left(\delta^{202} \mathrm{Hg} \times 0.252\right) \\
& \Delta^{201} \mathrm{Hg}=\delta^{201} \mathrm{Hg}-\left(\delta^{202} \mathrm{Hg} \times 0.752\right)
\end{aligned}
$$

Analytical uncertainty was estimated based on replication of the UM-Almadén standard solution and full procedural analyses of fish tissue standards ERM-CE464 and DORM-3 and is given in Supplementary Table S4.

Estimate of per cent photochemical demethylation. The proportion of $\mathrm{MMHg}$ that was photochemically demethylated before entry into the base of the food web was estimated following the method of ref. 20 unmodified, and as modified by ref. 22, to obtain the range of values reported in the text. The first method uses the observed $\Delta^{199} \mathrm{Hg}$ value and the fractionation factor determined experimentally ${ }^{20}$ using $1 \mathrm{mg}^{-1}$ DOC and much higher $\mathrm{MMHg} / \mathrm{DOC}$ than present in surface ocean water. The second method extrapolates the fractionation factor to the approximate $\mathrm{MMHg} / \mathrm{DOC}$ of surface ocean water using two published experiments and the assumption that there is no fractionation of the $\Delta^{199} \mathrm{Hg}$ value at $\mathrm{DOC}=0$ (ref. 22). Estimates of per cent photochemical degradation using the first method are about twice as high as estimates using the second method, but the proportional shift in photochemical degradation with depth is the same with both methods. Neither method considers the effect of salinity on fractionation of $\Delta^{199} \mathrm{Hg}$ and further experiments will be needed to refine estimates of the per cent photochemical degradation of $\mathrm{MMHg}$ based on $\Delta^{199} \mathrm{Hg}$.

Trophic position. Tissue samples for AA-CSIA were prepared as described in ref. 38 by acid hydrolysis followed by derivatization to produce trifluoroacetic amino acid esters and analysed using either a Delta V plus or MAT 253 mass spectrometer. Relative trophic position was estimated using differences between the $\delta^{15} \mathrm{~N}$ values of glutamic acid $\left(\delta^{15} \mathrm{~N}_{\text {glu }}\right)$ and phenylalanine $\left(\delta^{15} \mathrm{~N}_{\text {phe }}\right)$ and equation 7 of ref. 39 assuming the difference between $\delta^{15} \mathrm{~N}_{\text {glu }}$ and $\delta^{15} \mathrm{~N}_{\text {phe }}$ in marine algae $(\beta)$ is $3.4 \pm 0.9 \%$ and the ${ }^{15} \mathrm{~N}$ enrichment in glutamic acid relative to phenylalanine during trophic transfer $(\Delta)$ is $7.6 \pm 1.1 \%$. Uncertainty in trophic position was calculated by propagation of errors ${ }^{38}$ and is treated quantitatively using the analytical solution of differentiation of equation 7 of ref. 39 :

$$
\begin{gathered}
\sigma_{\mathrm{TP}}^{2}=\left(\frac{\partial T P}{\partial \delta^{15} \mathrm{~N}_{\mathrm{glu}}}\right)^{2} \sigma_{\delta^{15} \mathrm{~N}_{\mathrm{glu}}}^{2}+\left(\frac{\partial T P}{\partial \delta^{15} N_{\text {phe }}}\right)^{2} \sigma_{\delta^{15} N_{\text {phe }}}^{2} \\
+\left(\frac{\partial T P}{\partial \beta}\right)^{2} \sigma_{\beta}^{2}+\left(\frac{\partial T P}{\partial \Delta}\right)^{2} \sigma_{\Delta}^{2}
\end{gathered}
$$

Analytical uncertainty in $\delta^{15} \mathrm{~N}_{\text {glu }}$ and $\delta^{15} \mathrm{~N}_{\text {phe }}$ values in samples is based on replicate analyses at least in triplicate (Supplementary Table S3). Routine bulk tissue $\mathrm{C}$ and $\mathrm{N}$ isotopic compositions were determined using an online $\mathrm{C}-\mathrm{N}$ analyser coupled with an isotope ratio mass spectrometer.

\section{Received 24 March 2013; accepted 15 July 2013; published online} 25 August 2013

\section{References}

1. Sunderland, E. M. Mercury exposure from domestic and imported estuarine and marine fish in the US seafood market. Environ. Health Perspect. 115, 235-242 (2007).

2. Fitzgerald, W. F., Lamborg, C. H. \& Hammerschmidt, C. R. Marine biogeochemical cycling of mercury. Chem. Rev. 107, 641-662 (2007).

3. Sunderland, E. M., Krabbenhoft, D. P., Moreau, J. W., Strode, S. A. \& Landing, W. M. Mercury sources, distribution, and bioavailability in the North Pacific Ocean: Insights from data and models. Glob. Biogeochem. Cycles 23, GB2010 (2009).

4. Hammerschmidt, C. R. \& Bowman, K. L. Vertical methylmercury distribution in the subtropical North Pacific Ocean. Mar. Chem. 132-133, 77-82 (2012)

5. Cossa, D. et al. Mercury in the Southern Ocean. Geochim. Cosmochim. Acta 75, 4037-4052 (2011).

6. Cossa, D., Averty, B. \& Pirrone, N. The origin of methylmercury in open Mediterranean waters. Limnol. Oceanogr. 54, 837-844 (2009).
7. Mason, R. P. \& Fitzgerald, W. F. Alkylmercury species in the equatorial Pacific. Nature 347, 457-459 (1990).

8. Choy, C. A., Popp, B. N., Kaneko, J. J. \& Drazen, J. C. The influence of depth on mercury levels in pelagic fishes and their prey. Proc. Natl Acad. Sci. USA 106, 13865-13869 (2009).

9. Cossa, D. et al. Influences of bioavailability, trophic position, and growth on methylmercury in Hakes (Merluccius merluccius) from Northwestern Mediterranean and Northeastern Atlantic. Environ. Sci. Technol. 74, 4885-4893 (2012).

10. Mason, R. P. et al. Mercury biogeochemical cycling in the ocean and policy implications. Environ. Res. 119, 101-117 (2012).

11. Bloom, N. S. On the chemical form of mercury in edible fish and marine invertebrate tissue. Can. J. Fish. Aquat. Sci. 49, 1010-1017 (1992).

12. Van der Velden, S., Dempson, J. B., Evans, M. S., Muir, D. C. G. \& Power, M Basal mercury concentrations and biomagnification rates in freshwater and marine food webs: Effects on Arctic charr (Salvelinus alpinus) from eastern Canada. Sci. Total Environ. 444, 531-542 (2013).

13. Mason, R. P. \& Fitzgerald, W. F. The distribution and biogeochemical cycling of mercury in the equatorial Pacific Ocean. 40, 1897-1924 (1993).

14. Cossa, D., Martin, J. M., Takayanagi, K. \& Sanjuan, J. The distribution and cycling of mercury species in the western Mediterranean. Deep Sea Res. II 44, 721-740 (1997).

15. Monperrus, M. et al. Mercury methylation, demethylation and reduction rates in coastal and marine surface waters of the Mediterranean Sea. Mar. Chem. 107, 49-63 (2007)

16. Lehnherr, I. St, Louis, V. L., Hintelmann, H. \& Kirk, J. L. Methylation of inorganic mercury in polar marine waters. Nature Geosci. 4, 298-302 (2011).

17. Heimbürger, L. E. et al. Methyl mercury distributions in relation to the presence of nano and picophytoplankton in an oceanic water column (Ligurian Sea, North-western Mediterranean). Geochim. Cosmochim. Acta 74, 5549-5559 (2010)

18. Kraepiel, A. M., Keller, K., Chin, H. B., Malcolm, E. G. \& Morel, F. M. Sources and variations of mercury in tuna. Environ. Sci. Technol. 37, 5551-5558 (2003).

19. Blum, J. D. in Handbook of Environmental Isotope Geochemistry (ed. Baskaran, M.) Ch. 15, 229-246 (Springer, 2011).

20. Bergquist, B. A. \& Blum, J. D. Mass-dependent and -independent fractionation of $\mathrm{Hg}$ isotopes by photo-reduction in aquatic systems. Science 318, 417-420 (2007)

21. Senn, D. B. et al. Stable isotope (N, C, Hg) study of methylmercury sources and trophic transfer in the northern Gulf of Mexico. Environ. Sci. Technol. 44, 1630-1637 (2010)

22. Point, D. et al. Methylmercury photodegradation influenced by sea-ice cover in Arctic marine ecosystems. Nature Geosci. 4, 188-194 (2011).

23. McClelland, J. W. \& Montoya, J. P. Trophic relationships and the nitrogen isotopic composition of amino acids in plankton. Ecology 83, 2173-2180 (2002).

24. Rodriguez-Gonzalez, P. Species-specific stable isotope fractionation of mercury during $\mathrm{Hg}(\mathrm{II})$ methylation by an anaerobic bacteria (Desulfobulbus propionicus) under dark conditions. Environ. Sci. Technol. 43, 9183-9188 (2009).

25. Kritee, K., Barkay, T. \& Blum, J.D. Mass dependent stable isotope fractionation of mercury during microbial degradation of methylmercury. Geochim. Cosmochim. Acta 73, 1285-1296 (2009).

26. Gantner, N., Hintelmann, H., Zheng, W. \& Muir, D. C. Variations in stable isotope fractionation of $\mathrm{Hg}$ in food webs of Arctic lakes. Environ. Sci. Technol. 43, 9148-9154 (2009).

27. Laffont, L. et al. Anomalous mercury isotopic compositions of fish and human hair in the Bolivian Amazon. Environ. Sci. Technol. 43, 8985-8990 (2009).

28. Perrot, V. et al. Higher mass-independent isotope fractionation of methylmercury in the pelagic food web of Lake Baikal (Russia). Environ. Sci. Technol 46, 5902-5911 (2012).

29. Sherman, L. S. \& Blum, J. D. Mercury stable isotopes in sediments and largemouth bass from Florida lakes, USA. Sci. Total Environ. 448, 163-175 (2013).

30. Gehrke, G. E., Blum, J. D., Slotton, D. G. \& Greenfield, B. K. Mercury isotopes link mercury in San Francisco Bay forage fish to surface sediments. Environ. Sci. Technol. 4, 1264-1270 (2011).

31. Kritee, K., Blum, J. D., Johnson, M. W., Bergquist, B. \& Barkay, T. Mercury stable isotope fractionation during reduction of $\mathrm{Hg}(\mathrm{II})$ to $\mathrm{Hg}(0)$ by mercury resistant bacteria. Environ. Sci. Technol. 4, 1889-1895 (2007).

32. Donovan, P. M., Blum, J. D., Yee, D., Gehrke, G. E. \& Singer, M. B. An isotopic record of mercury in San Francisco Bay sediment. Chem. Geol. 349-350, 87-98 (2013).

33. Sherman, L. S., Blum, J. D., Keeler, G. J., Demers, J. D. \& Dvonch, J. T. Investigation of mercury pollution from a coal fired power plant using mercury isotopes. Environ. Sci. Technol. 46, 382-390 (2012).

34. Zheng, W. \& Hintelmann, H. Isotope fractionation of mercury during its photochemical reduction by low-molecular-weight organic compounds. J. Phys. Chem. A 114, 4246-4253 (2010). 
35. Kwon, S. Y. et al. Absence of fractionation of mercury isotopes during trophic transfer of methylmercury to freshwater fish in captivity. Environ. Sci. Technol. 46, 7527-7534 (2012).

36. Stramma, L. et al. Expansion of oxygen minimum zones may reduce available habitat for tropical pelagic fishes. Nature Clim. Change 2, 33-37 (2012).

37. Stramma, L., Johnson, G. C., Sprintall, J. \& Mohrholz, V. Expanding oxygen-minimum zones in the tropical oceans. Science 320, 655-658 (2008).

38. Choy, C. A. et al. Global trophic position comparison of two dominant mesopelagic fish families (Myctophidae, Stomiidae) using amino acid nitrogen isotopic analyses. PLoS ONE 7, e50133 (2012).

39. Chikaraishi, Y. et al. Determination of aquatic food-web structure based on compound-specific nitrogen isotopic composition of amino acids. Limnol. Oceanogr. Methods 7, 740-750 (2009).

\section{Acknowledgements}

We thank J. Pitz, A. Asato and S. Bailey for assistance with THg analyses; and K. Bussche and observers of the PIRO Longline Observer Program for sample collection. Financial support was provided to J.D.B. by the John D MacArthur Professorship and National Science Foundation (NSF) grant EAR-0952108. Additional financial support was provided by NSF grant OCE-1041329 (to B.N.P and J.C.D.), the Pelagic Fisheries
Research Program (to J.C.D. and B.N.P.) and University of Hawaii Sea Grant Award RFM-27PD. Any opinions, findings and conclusions or recommendations expressed in this material are those of the authors and do not necessarily reflect the views of the NSF or NOAA. This is SOEST contribution number 8947.

\section{Author contributions}

J.D.B. supervised $\mathrm{Hg}$ isotope measurements and co-wrote the manuscript, B.N.P. supervised determinations of trophic position and co-wrote the manuscript, J.C.D. supervised sample collection and contributed to data interpretation, C.A.C. carried out $\mathrm{Hg}$ concentration and $\mathrm{N}$ isotope measurements and contributed to data interpretation, and M.W.J. carried out $\mathrm{Hg}$ isotope measurements and contributed to data interpretation.

\section{Additional information}

Supplementary information is available in the online version of the paper. Reprints and permissions information is available online at www.nature.com/reprints. Correspondence and requests for materials should be addressed to J.D.B.

\section{Competing financial interests}

The authors declare no competing financial interests. 